\title{
A Cooperative Interlibrary Loan Service for the State-Assisted University Libraries in Ohio*
}

\begin{abstract}
This paper describes the cooperatively funded reference and interlibrary loan service located at Ohio State University which serves the twelve state-assisted universities in Ohio. During its first year, fiscal year 1969-70, this service received 7,126 requests, filled six out of seven requests, and provided other locations for two-thirds of the unfilled requests. Each request cost approximately $\$ 2.44$ to fill, exclusive of photocopy charges, and required .514 man hours. Mean cycle time for processing was 5.45 working days.
\end{abstract}

\begin{abstract}
A t their semiannual meeting in April 1968, the directors of the libraries at the twelve state-assisted universities in Ohio (Inter-University Library Council) discussed various aspects of interlibrary loan activities. Three issues seemed to dominate this discussion: (1) that eleven of these universities were borrowing heavily from one-Ohio State University; (2) that undergraduates were generally excluded from interlibrary loan services; and (3) that interlibrary lending was expensive and timeconsuming.

The ALA Interlibrary Loan Code is something less than liberal in its philosophy. The ALA model code for state, re-

- Expanded and revised version of a paper presented at the semiannual meeting of the Dayton-Miami Valley Consortium-Library Division meeting in Dayton, Ohio, on Wednesday, November 19, 1969.
\end{abstract}

Mr. Schmidt is a doctoral fellow in the School of Library Science at Florida State University, currently on leave as head of undergraduate libraries at Ohio State University. Kay Shaffer is IULC-RAILS librarian at Ohio State University. gional, and local interlibrary loan agreements is not much better. As usual, undergraduates receive lowest priority. For example, under the national code, an undergraduate would be denied a service at his college library which he could get through his local public library if he could convince them that the material was badly needed. To paraphrase the code, an undergraduate apparently does no research worthy of the name, and in any event, does not contribute to the "furtherance of knowledge" which "is in the general interest."

As a result of the April 1968 discussions, Ohio State University prepared a proposal to establish a cooperatively funded interlibrary loan and reference service dedicated to serving the eleven member institutions-all of them stateassisted university libraries-in Ohio. This proposal was presented to the IULC at its October 1968 meeting and approved. The service, RAILS (Reference and Interlibrary Loan Service), began operations July 1, 1969. This paper is a report on the RAILS experiment based on data through June 30, 1970, 
i.e., the first twelve months of operation.

The primary mission of RAILS is to increase access to the resources of Ohio State University libraries and to do so in a way which simplifies the user's task as much as possible. Members of the Ohio College Library Center, which includes the eleven RAILS participants, have been extended direct borrowing privileges by OSU for their faculty. In addition to special loan privileges, RAILS also offers professional reference assistance to all students and faculty of its member institutions who call or visit the Ohio State University libraries.

The first problem we encountered in setting up RAILS was the usual lacunae in the literature of librarianship. ${ }^{1}$ Nowhere were we able to discover benchmark data on turnaround time, unit costs, predictors of level of activity, etc., for interlibrary loans. This being the case, the initial budget and staff structure were based primarily on best estimates. The estimated budget and the actual expenses are compared in Table 1.

TABLE 1

FinANCES IULC-RAILS FisCAL Year 1969-70

\begin{tabular}{|c|c|c|}
\hline & Estimated & Actual \\
\hline \multirow{10}{*}{$\begin{array}{l}\text { Salaries and wages } \\
\text { Fringe benefits } \\
\text { Equipment } \\
\text { Communications (Post- } \\
\text { age, Telephone, } \\
\text { Teletype) } \\
\text { Travel } \\
\text { Photocopies ( } 1,500 / \\
\text { member @ } \\
\$ .03 / \text { copy) } \\
\text { Photocopies (1,500/ } \\
\text { member @ } \\
\$ .05 / \text { copy) }\end{array}$} & $\$ 13,976.00$ & $\$ 13,771.20$ \\
\hline & $-0-$ & $1,982.33$ \\
\hline & 400.00 & 166.00 \\
\hline & & \\
\hline & 400.00 & $1,290.00$ \\
\hline & -0 & 200.00 \\
\hline & & \\
\hline & & \\
\hline & & 825.00 \\
\hline & $\$ 15,226.00$ & $\$ 18,234.53$ \\
\hline
\end{tabular}

The budget deficit can be attributed primarily to three sources: omission of fringe benefits in the original budget estimates; an unrealized expectation that photocopy charges would be made at cost (\$03.5/page); and a large under- estimate of communication costs (postage, telephone, teletype).

We have analyzed the data from our first year to develop some measures of cost and performance for administrative purposes. These data show an annual level of activity of 7,126 transactions. If the total transactions for the year are divided into the total expenditures ( $\mathrm{Ta}$ ble 1) less photocopy charges, the resultant estimated cost per transaction is $\$ 2.44$, exclusive of copying costs. This translates into .514 man hours per transaction. It must be pointed out that this cost is unidirectional; i.e., for "loans to" only, because RAILS does no borrowing from its members. The unit cost and time data, although useful for planning the future of RAILS, are less meaningful than they might be because of the absence of comparable data in the literature and because we did not amortize collection or equipment costs (most of the necessary equipment was secured at no cost from the surplus inventory on campus), nor did we compute per square foot costs for physical plant maintenance.

Based on the first year (1 July 1969 30 June 1970) of operation, we discovered some interesting facts about our eleven users. Using rank-order correlations (Table 2), we found that the volume of usage of RAILS by its members does not correlate with size of collection $(\mathrm{r}=-.236) .^{2}$ The correlation coefficients with enrollment $(\mathrm{r}=.400)$ and with number of subscriptions $(\mathrm{r}=.373)$ are stronger than with size of collection but are still not statistically significant. It is also interesting to note that the correlation between volume of usage and percent of request unfilled $(\mathrm{r}=-.105)$ is only modestly negative, indicating that users are not noticeably deterred by a "no" from the system.

Given these correlation coefficients, we suspect that the dominant factor influencing usage of RAILS is the service orientation of the library director and 
staff at each member institution. If this orientation could be measured, we could probably test the validity of this hypothesis. ${ }^{3}$ Furthermore, geographic proximity of a RAILS member to other significant library collections may also influence the usage of RAILS. All other differences aside, contrast the location of Ohio University in Athens, Ohio, with that of Cleveland State University, for example.

An analysis of the kinds of requests received by RAILS (Table 3 ) indicates that photocopies fill approximately 71.3 percent of the requests, virtually all of which are of journals; 28.7 percent of the requests are for books. ${ }^{4}$ This contrasts with data from a survey completed recently at Case Western Reserve which reported that among academic libraries in Ohio, "loaned items" (as contrasted with photoduplication requests) accounted for 81.26 percent of the ILL activity. ${ }^{5}$ We also found that about one request in six cannot be filled for one or more of the following reasons: the item is not owned; is in circulation; is on reserve; or occasionally, is inexplicably lost.

In order to measure more precisely the effect of different factors on the services of RAILS, a 10 percent random sample of all transaction slips was selected for detailed analysis. Table 4 shows the breakdown of the sample by type (Loan, Photoduplication) and by status (Filled, Unfilled). The sample totals (Table 4) and the population totals (Table 3) are very similar. The percent of unfilled requests in the sample (17.7) compares realistically with the percent unfilled in the population (17.4); the breakdown by type is also comparable (71.3 percent photoduplication in the population versus 66.5 percent in the sample).

Analysis of the sample by quarter (Table 5) confirms what the monthly statistical reports from RAILS during

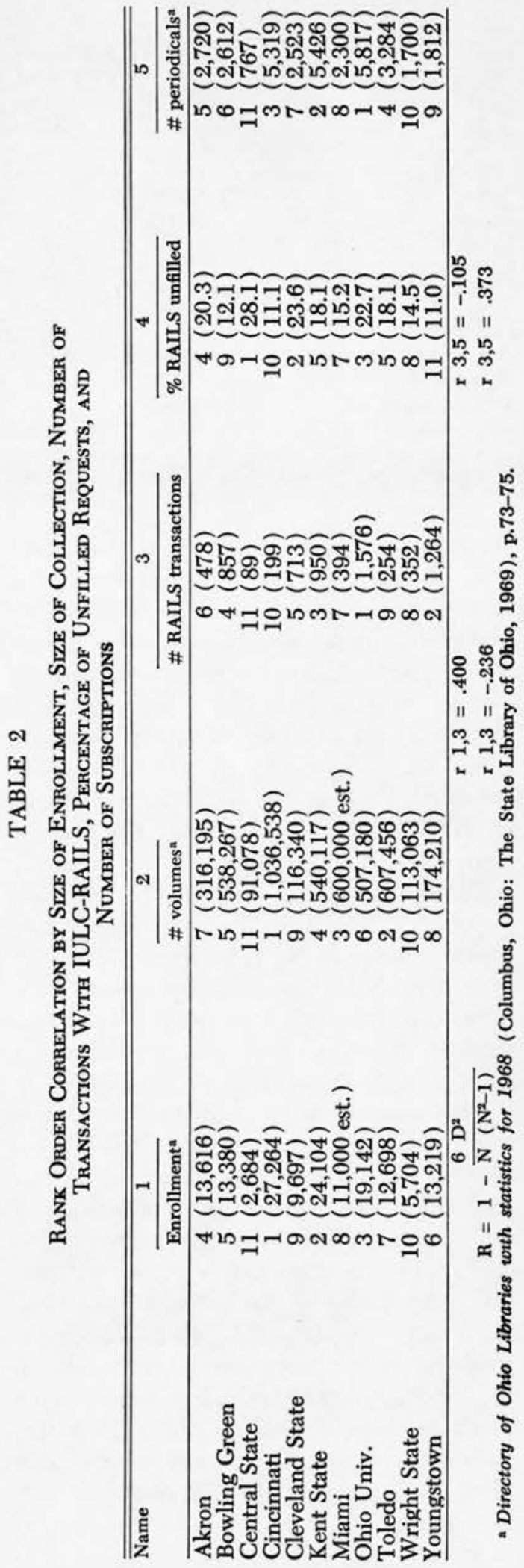


TABLE 3

RAILS Statistics BY INSTITUTION FOR Fiscal YeAR 1969-70

\begin{tabular}{|c|c|c|c|c|c|}
\hline & $\begin{array}{l}\text { No. pages } \\
\text { photocopy }\end{array}$ & $\begin{array}{l}\text { No. requests } \\
\text { photocopy }\end{array}$ & $\begin{array}{l}\text { No. vols. } \\
\text { lent }\end{array}$ & $\begin{array}{l}\text { No. unfilled } \\
\text { requests }\end{array}$ & $\begin{array}{c}\text { Total } \\
\text { requests }\end{array}$ \\
\hline Akron & 1706 & 132 & 134 & 97 & 478 \\
\hline Bowling Green & 4705 & 179 & 186 & 104 & 857 \\
\hline Central State & 138 & 16 & 45 & 25 & 89 \\
\hline Cincinnati & 1265 & 133 & 45 & 22 & 199 \\
\hline Cleveland State & 3187 & 380 & 160 & 168 & 713 \\
\hline Kent State & 4884 & 552 & 221 & 172 & 950 \\
\hline Miami & 1641 & 227 & 106 & 60 & 394 \\
\hline Ohio University & 5805 & 802 & 440 & 357 & 1576 \\
\hline Toledo & 837 & 97 & 99 & 46 & 254 \\
\hline Wright State & 1442 & 186 & 115 & 51 & 352 \\
\hline Youngstown State & 8763 & 990 & 134 & 139 & 1264 \\
\hline Total & 34,373 & 3,694 & 1,685 & 1,241 & 7,126 \\
\hline
\end{tabular}

the year had indicated; i.e., that neither the mix by type nor the mix by status varied widely during the year. The requests for loans always ranged between 29-36 percent and the unfilled requests always ranged between 14-19 percent. However, an analysis of the mean cycle times for a request by quarter (Table 6 ) revealed that as the volume increased, so did the mean cycle time. The exception to this was the summer quarter 1969 which was the time in which search sequences, duplicating procedures, and routines were being established. The apparent relationship between mean cycle time and volume of activity may, upon further study, reveal some interesting data on optimal workload per employee.

The sample was analyzed to determine the reasons for the unfilled requests. It had been feared by some that the added demands on the collections of Ohio State by RAILS might prove a disservice to the university's primary clientele and provoke an adverse reaction. However, the data in Table 7 indicate that the same materials were rarely in demand simultaneously by both groups of users. Nearly half of the unfilled requests (46.4 percent) could not be supplied because the title requested was not owned. If the three most common
TABLE 4

Number oe Requests in 10\% Random Sample by Type and Status

\begin{tabular}{|c|c|c|c|c|}
\hline \multirow[b]{2}{*}{ PD } & \multicolumn{2}{|r|}{$\%$} & \multirow[b]{2}{*}{$\begin{array}{c}100.0 \\
(\mathrm{~N}=471)\end{array}$} & \multirow[b]{2}{*}{$66.5 \%$} \\
\hline & $\begin{array}{c}\mathrm{F} \\
87.9\end{array}$ & $\begin{array}{r}\text { UF } \\
12.1\end{array}$ & & \\
\hline Loan & $\begin{array}{r}71.3 \\
(\mathrm{~N}=583) \\
82.3 \%\end{array}$ & $\begin{array}{r}28.7 \\
(\mathrm{~N}=125) \\
17.7 \%\end{array}$ & $\begin{array}{c}100.0 \\
\left(\begin{array}{c}\mathrm{N}=237 \\
\mathrm{~N}=708\end{array}\right)\end{array}$ & $33.5 \%$ \\
\hline
\end{tabular}

$$
\begin{aligned}
\text { PD } & =\text { Photocopy } \\
\text { F } & =\text { Filled } \\
\text { UF } & =\text { Unfilled }
\end{aligned}
$$

causes for unfilled requests are combined, they account for nearly nine cases out of ten, or 87.2 percent. As an added service to RAILS members, other locations were automatically provided for unfilled requests whenever possible unless instructions to the contrary were received. Thus, as noted on Table 7, for two-thirds of the unfilled requests, users were given location information.

Tables 8,9 , and 10 analyze the sample by the medium of communication used, by language of publication, and by type or format of publication. In spite of our urgings to be more flexible, RAILS members seem to prefer the standard ALA interlibrary loan form as the medium of communication, although the volume by 
Cooperative Interlibrary Loan Service / 201

TABLE 5

Distribution of Transactions in 10\% Random Sample by Quarter and by Type aNd Status

\begin{tabular}{|c|c|c|c|c|c|c|}
\hline & & \multicolumn{2}{|c|}{$\%$} & \multicolumn{2}{|c|}{$\%$} & \\
\hline & & Loan & $\mathrm{PD}$ & F & UF & \\
\hline \multirow[t]{2}{*}{1969} & July-Sept. & 29.1 & 70.9 & 86.0 & 14.0 & $(\mathrm{~N}=86)$ \\
\hline & Oct.-Dec. & 36.0 & 64.0 & 84.0 & 16.0 & $(\mathrm{~N}=175)$ \\
\hline \multirow[t]{3}{*}{1970} & Jan.-March & 35.1 & 64.9 & 80.5 & 19.5 & $(\mathrm{~N}=251)$ \\
\hline & April-June & 31.1 & 68.9 & 81.6 & 18.4 & $(\mathrm{~N}=196)$ \\
\hline & & $\begin{array}{c}(\mathrm{N}=237) \\
33.5 \%\end{array}$ & $\begin{array}{c}(\mathrm{N}=471) \\
66.5 \%\end{array}$ & $\begin{array}{c}(\mathrm{N}=583) \\
82.3 \%\end{array}$ & $\begin{array}{c}\left(\begin{array}{c}N=125) \\
17.7 \%\end{array}\right)\end{array}$ & \\
\hline
\end{tabular}

TABLE 6

Analysis of Cycle Times by Quarter

\begin{tabular}{|c|c|c|c|c|c|c|}
\hline $\operatorname{Day}(s)$ & Percent & $\mathrm{f}$ & $\underset{(f)}{\text { Summer }}$ & $\begin{array}{c}\text { Fall } \\
\text { (f) }\end{array}$ & $\begin{array}{l}\text { Winter } \\
\text { (f) }\end{array}$ & $\underset{\text { (f) }}{\text { Spring }}$ \\
\hline 1 & 28.7 & 203 & (23) & (74) & (46) & $(60)$ \\
\hline 2 & 18.6 & 132 & (16) & (37) & (51) & (28) \\
\hline 3 & 17.4 & 123 & (15) & (24) & (49) & $(35)$ \\
\hline 4 & 8.1 & 57 & (2) & (11) & (27) & (17) \\
\hline 5 & 7.3 & 52 & (12) & (6) & (18) & (16) \\
\hline 6 & 3.4 & 24 & (6) & (1) & (10) & (7) \\
\hline 7 & 1.3 & 9 & (2) & (1) & (2) & (4) \\
\hline 8 & 1.3 & 9 & (3) & (2) & $(3)$ & (1) \\
\hline 9 & .6 & 4 & $0.0(0)$ & (1) & (2) & (1) \\
\hline $10-14$ & 5.2 & 37 & (4) & (10) & (14) & (9) \\
\hline $15-19$ & 2.8 & 20 & (2) & (5) & (6) & (7) \\
\hline $20-24$ & .8 & 6 & (1) & (1) & (4) & $0.0(0)$ \\
\hline $25-29$ & 1.3 & 9 & $0.0(0)$ & $0.0(0)$ & (7) & (2) \\
\hline \multirow{4}{*}{$\begin{array}{c}30-39 \\
40+\end{array}$} & 1.8 & 13 & $0.0(0)$ & (1) & (9) & (3) \\
\hline & 1.4 & 10 & $0.0(0)$ & (1) & (3) & (6) \\
\hline & 100.0 & & & & & \\
\hline & & $(\mathrm{N}=708)$ & $(\mathrm{N}=86)$ & $(\mathrm{N}=175)$ & $(\mathrm{N}=251)$ & $(\mathrm{N}=196)$ \\
\hline Mean: & - & 5.45 & 4.06 & 3.77 & 6.59 & 6.09 \\
\hline Median: & - & 3.00 & 3.00 & 2.00 & 3.00 & 2.00 \\
\hline
\end{tabular}

TABLE 7

Analysis of Reasons For UNFILLED REQUESTS

\begin{tabular}{lrr}
\hline \hline & $\mathrm{f}$ & Percent \\
\hline Not owned & 58 & 46.4 \\
Item missing & 27 & 21.6 \\
Issue not received & 24 & 19.2 \\
In use & 11 & 8.8 \\
Noncirculating & 4 & 3.2 \\
Other & 1 & 0.8 \\
& 125 & 100.0
\end{tabular}

Other locations provided in 83 of 125 cases or $66.4 \%$.
TABLE 8

Analysis of Transactions by Communication Medium

\begin{tabular}{|c|c|c|c|c|}
\hline & \multirow[b]{2}{*}{ Percent } & \multicolumn{2}{|r|}{$\%$} & \\
\hline & & F & UF & \\
\hline ALA form & 80.2 & 83.3 & 16.7 & $(\mathrm{~N}=568)$ \\
\hline Teletype & 13.0 & 77.2 & 22.8 & $(\mathrm{~N}=92)$ \\
\hline Telephone & 6.6 & 80.9 & 19.1 & $(\mathrm{~N}=47)$ \\
\hline \multirow[t]{2}{*}{ In person } & 0.2 & 100.0 & 0.0 & $(\mathrm{~N}=1)$ \\
\hline & 100.0 & $(\mathrm{~N}=583)$ & $(\mathrm{N}=125)$ & $(\mathrm{N}=708)$ \\
\hline
\end{tabular}


TABLE 9

ANALysis of Transactions BY

Language of Publication

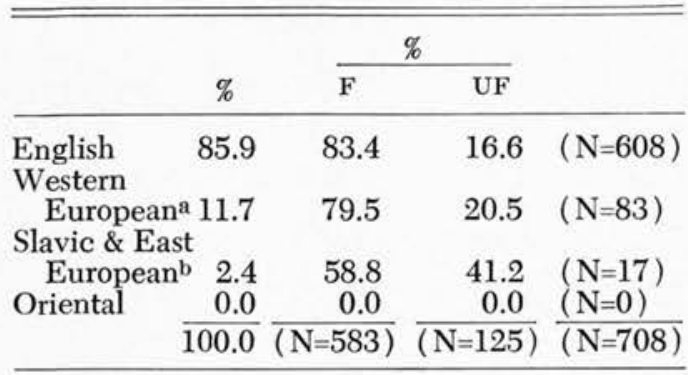

a Non-English but Roman alphabet.

b Non-English and non-Roman alphabet (excluding oriental).

TABLE 10

Analysis by Type of Publication

\begin{tabular}{|c|c|c|c|c|}
\hline & \multirow[b]{2}{*}{$\%$} & \multicolumn{2}{|r|}{$\%$} & \\
\hline & & $\mathrm{F}$ & UF & \\
\hline Seriala $^{\mathrm{a}}$ & 65.7 & 88.6 & 11.4 & $(\mathrm{~N}=465)$ \\
\hline Monograph & 26.1 & 72.4 & 27.6 & $(\mathrm{~N}=185)$ \\
\hline Thesis & 2.5 & 66.7 & 33.3 & $(\mathrm{~N}=18)$ \\
\hline Govt. Doc. & 3.0 & 42.9 & 57.1 & $(\mathrm{~N}=21)$ \\
\hline Microform & 2.3 & 93.8 & 6.2 & $(\mathrm{~N}=16)$ \\
\hline \multirow[t]{2}{*}{ Other } & 0.4 & 33.3 & 66.7 & $(\mathrm{~N}=3)$ \\
\hline & $\overline{100.0}$ & $\mathrm{~N}=$ & $(\mathrm{N}=$ & $(\mathrm{N}=708)$ \\
\hline
\end{tabular}

a Published at regular intervals (includes monographic series and conference proceedings).

teletype can be expected to increase as more members install equipment. The volume by telephone does not yet justify an outward WATS line, although this too may change. The analysis by language reflects an overwhelming majority (85.9 percent) of the requests for English language materials. Although Ohio State is at or near the level of primary excellence in Slavic materials, this collection does not seem to be in great demand among RAILS members. Analysis by type of publication (Table 10) reflects the same pattern shown in Table 4 ; i.e., that photoduplication (usually for journals) comprises a large majority of the business of RAILS. Given that Ohio State has long participated in both NUC and ULS, this majority may indicate that the serials holdings are stronger than the monograph collection.

Finally, the sample was analyzed to determine the effect of different variables on the mean and median cycle times. As shown in Table 11, it takes longer to report that a request cannot be filled than to fill it. The time required to copy an item makes the mean time for a photocopy transaction longer than when the original copy is lent. The mean time for government documents is the highest of all, possibly because of the complex forms of entry for many documents. Western European languages show a smaller mean than other language groups, with Slavic the highest. The telephone is the quickest medium of communication, followed by the teletype, and finally, mail. The teletype may well become more competitive as formats become more widely standardized. ${ }^{6}$

One of the major innovations RAILS has been able to effect is to reduce the level of detail and verification demanded of the user. Requests are handled as they come without imposing the burdens of complex forms and precise data on users. In spite of this, or perhaps because of it, the in-house cycle time for a request averages 5.45 working days, although frequently only one work day (eight hours) is required. However, there does appear to be a direct relationship between degree of accuracy and/or detail in a requester's citation and the length of the in-process time period. (Mean of 4.20 for requests which did not need verification compared with 11.05 for those which did.) This would tend to encourage verification by requesters, particularly when speed is important, but the RAILS staff is reluctant to become too insistent on this point since their willingness not to require extensive verification is viewed as a user service and a significant improvement over the regular ILL procedures.

Finally, the location of the item re- 
TABLE 11

Comparison of Mean and Median Cycle Times (IN Working DaYs)

\begin{tabular}{llrrr}
\hline \hline \multirow{2}{*}{ Total Sample } & & (f) & Mean & Median \\
\hline Status & & 708 & 5.45 & 3.00 \\
Type of request & Filled & 583 & 4.21 & 3.00 \\
Type of publication & Unfilled & 125 & 11.22 & 4.00 \\
& Loan & 237 & 6.06 & 2.00 \\
& PD & 471 & 5.14 & 3.00 \\
& Serial & 465 & 5.14 & 3.00 \\
& Monograph & 185 & 5.99 & 2.00 \\
& Thesis & 18 & 3.19 & 2.00 \\
& Govt. Doc. & 21 & 11.67 & 5.00 \\
Language of publication & Microform & 16 & 2.47 & 1.00 \\
& Other & 3 & 5.50 & 3.00 \\
& English & 608 & 5.63 & 3.00 \\
Medium of communication & 83 & 2.76 & 2.00 \\
& Western European & 17 & 7.32 & 2.00 \\
& Oriental & 0 & 0.00 & 0.00 \\
NLA form & Teletype & 568 & 5.67 & 3.00 \\
Need for verification & Telephone & 92 & 4.24 & 3.00 \\
\multirow{2}{*}{ Location (filled only) } & In person & 47 & 2.51 & 1.00 \\
& Yes & 1 & 1.00 & - \\
& No & 219 & 11.05 & 3.00 \\
& Main Library & 579 & 4.20 & 3.00 \\
& Other & 298 & 2.84 & 1.00 \\
& & 285 & 5.64 & 4.00 \\
\hline
\end{tabular}

quested in the system affected operational performance. Most university libraries, Ohio State among them, have separate libraries for the sciences and certain other disciplines scattered around the campus. If an item was located outside the main library, the cycle time doubled.

\section{Conclusion}

The future of RAILS is assured for at least a second year (1 July 1970-30 June 1971) with the present membership. In the meantime, a few private colleges in Ohio have inquired about participation in the system, and exploration of funding under Title III of LSCA by including other types of libraries as members has begun. It is fair to say that RAILS is a success.

This new addition to a growing list of successful cooperative ventures among academic and/or special libraries in Ohio augurs well for the future. This is especially true in view of Wyman Parker's pessimistic observations when he wrote The Possibility of Extensive Academic Library Cooperation in Ohio for the Ohio College Association in 1963. At that time he wrote:

Interlibrary loan is not the answer to this need of large resources by students who are now required to do individual work on the college campus. In fact, interlibrary loan has broken down already. (p.7)

It is a pleasure to announce that interlibrary loan is alive and well and living in Ohio.

\section{REFERENCES}

1. An exception to this generalization is Vern M. Pings, Interlibrary Loans: A Review of Library Literature, 1876-1965 (Detroit: Wayne State University, School of Medicine, Library, Biomedical Information Service Center, 1966). The author notes: "No sound quantitative data exists either on the flow of documents or on the cost of supporting such services." (p.17)

2. Hubert M. Blalock, Social Statistics (New York: McGraw-Hill, 1960), p.317. 
3. See for example Fred L. Adair, "The Development of a Scale to Measure the Service Orientation of Librarians: Preliminary Investigations" (Ph.D. diss., University of North Carolina, 1968).

4. The average photoduplication (journal) request is for 8.2 pages and an average book request is for one volume.

5. A. J. Goldwyn and Edward Verhosek, A Study of Extra Institutional Use of Libraries by Ohio Academic Personnel (Cleveland: Center for Documentation and Communications Research, School of Library Science, Case Western Reserve University, 1969), p.71.

6. See for example Warren Bird and G. S. T. Cavanagh, Teletypewriter Exchange System for Interlibrary Communication (Durham, N.C.: Duke University Medical Center Library, 1968). 